\title{
Two New Holostan-Type Triterpene Glycosides from the Sea Cucumber Bohadschia marmorata JAEGER
}

\author{
Weihua Yuan, ${ }^{a}$ Yanghua YI, ${ }^{*, a}$ Haifeng TAnG,,${ }^{b}$ Mei XuE, ${ }^{a}$ Zenglei WAng, ${ }^{a}$ Guoquan Sun, ${ }^{a}$ \\ Wen Zhang, ${ }^{a}$ Baoshu Liv, ${ }^{a}$ Ling LI, ${ }^{a}$ and Peng SuN ${ }^{a}$ \\ ${ }^{a}$ Research Center for Marine Drugs, School of Pharmacy, Second Military Medical University; 325 Guohe Road, \\ Shanghai 200433, P.R. China: and ${ }^{b}$ Department of Pharmacy, Xijing Hospital, Fourth Military Medical University; Xi'an \\ 710032, P. R. China. Received April 18, 2008; accepted May 23, 2008; published online May 27, 2008
}

Two new holostan-type triterpene glycosides, 17-hydroxy fuscocineroside B (1) and 25-hydroxy fuscocineroside B (2), together with a known triterpene glycoside, fuscocineroside B (3) were isolated from the sea cucumber Bohadschia marmorata JAEGER. The structures of the new triterpene glycosides were elucidated on the basis of spectroscopic analyses and chemical reactions. Compounds 1 and 3 showed considerable antifungal activities against six strains.

Key words sea cucumber; Bohadschia marmorata; triterpene glycoside, antifungal active

In order to find new biologically active substances from marine organisms, we have been studying kinds of sea cucumbers. $^{1-6)}$ Triterpene glycosides are the predominant secondary metabolites of the sea cucumber, and exhibit wide spectra of biological activity, such as antifungal, cytotoxic effects, ${ }^{4,7)}$ and they are usually of the lanosterol-type with a 18(20)-lactone and the sugar chain of up to six monosaccharide units is generally linked to the $\mathrm{C}-3$ of the aglycone, which are composed by D-xylose, D-quinovose, D-glucose, and 3-O-methyl-D-glucose. ${ }^{8)}$ In this paper, we report the isolation and the antifungal activity of the three glycosides from the sea cucumber Bohadschia marmorata JAEGER (family Bohadschia) [distribute abundantly in the South China Sea], and structural elucidation of the new triterpene glycosides.

\section{Results and Discussion}

The $60 \%$ EtOH extracts of B. marmorata JAEGER $(3.5 \mathrm{~kg}$, dried) were suspended in $\mathrm{H}_{2} \mathrm{O}$, partitioned with $n$-BuOH. The $n$ - $\mathrm{BuOH}$ extract was sequentially subjected to column chromatography on Si gel and ODS, and followed by HPLC on a Silasorb C-18 column to afford the pure 17-hydroxy fuscocineroside B (1), 25-hydroxy fuscocineroside B (2) and fuscocineroside B (3).

The known compound $\mathbf{3}$ was identified as fuscocineroside $\mathrm{B}$, originally isolated from the sea cucumber Holothuria fuscocinerea, by comparison of physical and spectroscopic data

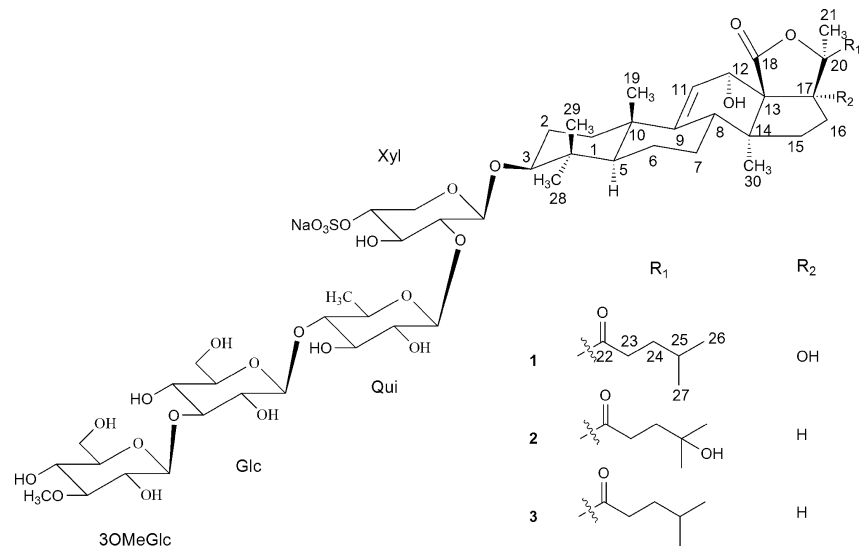

Fig. 1. The Structures of Compounds $\mathbf{1}-\mathbf{3}$
(MS and 2D-NMR) with literature values. ${ }^{5)}$

17-Hydroxy fuscocineroside B (1), colorless amorphous powder, was positive to Liebermann-Burchard and Molish tests. The molecular formula was established as $\mathrm{C}_{54} \mathrm{H}_{85} \mathrm{O}_{27} \mathrm{NaS}$ by the pseudomolecular ion $[\mathrm{M}+\mathrm{Na}]^{+}$at $m / z$ 1243.4805 in the HR-ESI-MS (positive-ion mode). A fragment ion peak at $m / z 1123\left[\mathrm{M}+\mathrm{Na}-\mathrm{NaHSO}_{4}\right]^{+}$in the positive ion mode ESI-MS indicated the presence of a sulfate group in 1, which was confirmed by the IR spectrum with absorption bands at 1265 and $1205 \mathrm{~cm}^{-1}$. The IR spectrum also showed the presence of hydroxyl $\left(3421 \mathrm{~cm}^{-1}\right)$, carbonyl $\left(1775,1717 \mathrm{~cm}^{-1}\right)$, olefinic $\left(1651 \mathrm{~cm}^{-1}\right)$.

The ${ }^{1} \mathrm{H}-,{ }^{13} \mathrm{C}-\mathrm{NMR}$, and DEPT spectra displayed resonances due to seven tertiary methyl groups, one olefinic bond $\left(\delta_{\mathrm{H}} 5.69 ; \delta_{\mathrm{C}} 154.3,115.5\right)$, one lactone carbonyl group $\left(\delta_{\mathrm{C}}\right.$ $173.8)$, and one doublet $\left(\delta_{\mathrm{H}} 5.06 ; \delta_{\mathrm{C}} 71.1\right)$ that was ascribed to a methine proton linked to a carbon bearing a hydroxy group and suggested that the aglycone of $\mathbf{1}$ had a holostane triterpenoid skeleton with a 9(11)-en-12-ol moiety. ${ }^{9)}$

The location of the ketone carbonyl group at C-22 was deduced from the chemical shift of the C-22 signal, which showed long-range correlation with the protons at $\delta_{\mathrm{H}} 2.00(\mathrm{~s}$, $\left.\mathrm{CH}_{3}-21\right)$ in the HMBC spectrum. The aglycone of $\mathbf{1}$ is similar to that of fuscocineroside $\mathrm{B}$ in spite of a hydroxyl instead of a $\alpha-\mathrm{H}$ at $\mathrm{C}-17 .^{5)}$ The signal of $\mathrm{C}-17$ was shifted downfield from 46.9 to $87.6 \mathrm{ppm}$. The carbon $\mathrm{C}-17\left(\delta_{\mathrm{C}} 87.6\right)$ showed long-rang correlation with the protons at $\delta_{\mathrm{H}} 2.00\left(\mathrm{~s}, \mathrm{CH}_{3}-21\right)$ and $\delta_{\mathrm{H}} 5.06(12-\mathrm{CH})$ in the HMBC spectrum.

The relative stereochemistry of all chiral centers of the aglycone was established with the aid of a NOESY experiment. Thus, as is depicted in Fig. 2, H-3 showed correlations with $\mathrm{H}-1$ (Xyl), $\mathrm{H}-1 \alpha$ (1.47 ppm), $\mathrm{H}-5 \alpha$ and $\mathrm{H}-28$ confirming the $\beta$ configuration at $\mathrm{C}-3$. The $12 \alpha$ configuration of the hydroxyl group was confirmed by a cross-peak at $\delta_{\mathrm{H}} 5.06$ $(\mathrm{H}-12) / 2.00(\mathrm{H}-21)$ in the NOESY spectrum and from the coupling constant for $\mathrm{H}-12$ with $\mathrm{H}-11(4.0 \mathrm{~Hz}){ }^{7)}$ A correlation between H-12 and H-21 in the NOESY spectrum, evidenced the $\alpha$ configuration of the hydroxyl group at $\left.\mathrm{C}-17,{ }^{10}\right)$ see Fig. 2. Complete assignments were achieved by studying the results of HMQC, HMBC, COSY, TOCSY and NOESY experiment (see Table 1, Fig. 2). Thus, the structure of the aglycone part of $\mathbf{1}$ was identified as a 22-oxo-9(11)- 




Fig. 2. The Key NOESY Correlations and Relative Configuration of $\mathbf{1}$

Table 1. ${ }^{1} \mathrm{H}$ - and ${ }^{13} \mathrm{C}-\mathrm{NMR}$ Chemical Shifts and Selected HMBC Correlations for the Aglycone Moiety of $\mathbf{1}$ and 2 (in Pyridine- $d_{5}, 400 / 100 \mathrm{MHz}$ )

\begin{tabular}{|c|c|c|c|c|c|c|}
\hline \multirow[b]{2}{*}{$\mathrm{C}$} & \multicolumn{3}{|c|}{1} & \multicolumn{3}{|c|}{2} \\
\hline & $\delta_{\mathrm{H}}$ mult. $(J$ in $\mathrm{Hz})$ & $\delta_{\mathrm{C}}$ & HMBC & $\delta_{\mathrm{H}}$ mult. $(J$ in $\mathrm{Hz})$ & $\delta_{\mathrm{C}}$ & HMBC \\
\hline 1 & $1.47,1.90 \mathrm{~m}$ & 36.5 & & $1.51,1.93 \mathrm{~m}$ & 36.6 & \\
\hline 2 & $2.02,2.19 \mathrm{~m}$ & 27.2 & & $2.20 \mathrm{~m}$ & 27.2 & \\
\hline 3 & 3.22 (overlap) & 88.9 & $4,28,29,1^{\prime}$ & 3.22 (overlap) & 88.9 & $4,28,29,1^{\prime}$ \\
\hline 4 & - & 40.1 & & - & 40.2 & \\
\hline 5 & $1.07 \mathrm{~m}$ & 52.8 & $3,4,6,10,19,28$ & $1.07 \mathrm{~m}$ & 52.9 & $3,4,6,10,19,28$ \\
\hline 6 & $1.56,1.80 \mathrm{~m}$ & 21.3 & & $1.78 \mathrm{~m}$ & 21.4 & \\
\hline 7 & $1.58,1.81 \mathrm{~m}$ & 28.5 & & $1.78 \mathrm{~m}$ & 29.0 & \\
\hline 8 & $3.37 \mathrm{~m}$ & 41.1 & $7,9,11,14,30$ & $3.39 \mathrm{~m}$ & 40.3 & $7,9,11,14,30$ \\
\hline 9 & - & 154.3 & & - & 153.3 & \\
\hline 10 & - & 39.9 & & - & 39.8 & \\
\hline 11 & $5.69 \mathrm{~d}(4.0)$ & 115.5 & $8,10,12,13$ & $5.79 \mathrm{~d}(4.1)$ & 116.1 & $8,10,12,13$ \\
\hline 12 & $5.06 \mathrm{~d}(4.0)$ & 71.1 & $9,11,14,18$ & $4.63 \mathrm{~d}(4.1)$ & 67.9 & $9,11,14,18$ \\
\hline 13 & - & 58.7 & & - & 64.0 & \\
\hline 14 & - & 46.4 & & - & 46.7 & \\
\hline 15 & $1.47,1.89 \mathrm{~m}$ & 36.9 & & $1.47,1.64 \mathrm{~m}$ & 37.2 & \\
\hline 16 & $2.24,2.51 \mathrm{~m}$ & 39.2 & & $2.25 \mathrm{~m}$ & 27.4 & \\
\hline 17 & - & 87.6 & & $3.73 \mathrm{~m}$ & 47.0 & \\
\hline 18 & - & 173.8 & & - & 176.9 & \\
\hline 19 & $1.45 \mathrm{~s}$ & 22.7 & $1,5,9,10$ & $1.47 \mathrm{~s}$ & 22.7 & $1,5,9,10$ \\
\hline 20 & - & 92.3 & & - & 90.6 & \\
\hline 21 & $2.00 \mathrm{~s}$ & 21.6 & $17,20,22$ & $1.87 \mathrm{~s}$ & 25.1 & $17,20,22$ \\
\hline 22 & - & 208.7 & & - & 211.6 & \\
\hline 23 & $2.87,2.98 \mathrm{~m}$ & 37.2 & & $3.24 \mathrm{~m}$ & 35.3 & \\
\hline 24 & $1.70 \mathrm{~m}$ & 32.6 & & $2.20 \mathrm{~m}$ & 37.4 & \\
\hline 25 & $1.62 \mathrm{~m}$ & 27.9 & & - & 69.0 & \\
\hline 26 & $0.95 \mathrm{~d}(6.5)$ & 22.6 & $24,25,27$ & $1.48 \mathrm{~s}$ & 30.2 & $24,25,27$ \\
\hline 27 & $0.95 \mathrm{~d}(6.5)$ & 22.6 & $24,25,26$ & $1.48 \mathrm{~s}$ & 29.9 & $24,25,26$ \\
\hline 28 & $1.32 \mathrm{~s}$ & 28.2 & $3,4,5,29$ & $1.32 \mathrm{~s}$ & 28.2 & $3,4,5,29$ \\
\hline 29 & $1.12 \mathrm{~s}$ & 16.9 & $3,4,5,28$ & $1.13 \mathrm{~s}$ & 16.9 & $3,4,5,28$ \\
\hline 30 & $1.72 \mathrm{~s}$ & 20.0 & $8,13,14,15$ & $1.30 \mathrm{~s}$ & 22.0 & $8,13,14,15$ \\
\hline
\end{tabular}

holostene-3 $\beta, 12 \alpha, 17 \alpha$-triol.

The sugar moieties of $\mathbf{1}$ were determined to be D-xylose, D-glucose, D-quinovose and 3-O-methyl-D-glucose in a $1: 1: 1: 1$ ratio by acidic hydrolysis with aqueous $2 \mathrm{M}$ trifluoroacetic acid and preparation of the corresponding aldononitrile peracetates, which were analyzed by GC-MS using standard aldononitrile peracetates as reference samples. The common D-configuration for the four carbohydrate units was assumed also according to those most often encountered among the sea cucumber glycosides. ${ }^{11,12)}$

The ${ }^{1} \mathrm{H}-,{ }^{13} \mathrm{C}-\mathrm{NMR}$ and DEPT spectra displayed signals for four anomeric protons and their corresponding carbons, $\delta_{\mathrm{H}} 4.76\left(\delta_{\mathrm{C}} 105.4\right), \delta_{\mathrm{H}} 5.12\left(\delta_{\mathrm{C}} 105.6\right), \delta_{\mathrm{H}} 5.06\left(\delta_{\mathrm{C}} 105.0\right)$ and $\delta_{\mathrm{H}} 5.42\left(\delta_{\mathrm{C}} 106.0\right)$. All anomeric protons were doublet with ${ }^{3} J_{\mathrm{H}-1 / \mathrm{H}-2}=6.4-7.6 \mathrm{~Hz}$, the large vicinal coupling constants of each anomeric proton indicated a trans-diaxial orientation with respect to their coupling partners ( $\beta$-configuration).

Complete assignment was achieved by studying the results of HMQC, HMBC, COSY and TOCSY experiment (Table 2). The HMQC experiment correlated all proton resonances with those of their corresponding carbons. The COSY exper- 
Table 2. $\quad{ }^{1} \mathrm{H}$ - and ${ }^{13} \mathrm{C}-\mathrm{NMR}$ Chemical Shifts and Selected HMBC Correlations for the Sugar Moiety of $\mathbf{1}$ and 2 (in Pyridine- $d_{5}, 400 / 100 \mathrm{MHz}$ )

\begin{tabular}{|c|c|c|c|c|c|c|}
\hline \multirow[b]{2}{*}{$\mathrm{C}$} & \multicolumn{3}{|c|}{1} & \multicolumn{3}{|c|}{2} \\
\hline & $\delta_{\mathrm{H}}$ mult. $(J$ in $\mathrm{Hz})$ & $\delta_{\mathrm{C}}$ & HMBC & $\delta_{\mathrm{H}}$ mult. $(J$ in Hz) & $\delta_{\mathrm{C}}$ & HMBC \\
\hline \multicolumn{7}{|l|}{ Xyl } \\
\hline 1 & $4.76 \mathrm{~d}(6.4)$ & 105.4 & C-3 (Aglycone) & $4.76 \mathrm{~d}(6.7)$ & 105.4 & C-3 (Aglycone) \\
\hline 2 & $4.12 \mathrm{~m}$ & 83.5 & & $4.12 \mathrm{~m}$ & 83.5 & \\
\hline 3 & $4.36 \mathrm{~m}$ & 75.4 & & $4.38 \mathrm{~m}$ & 75.4 & \\
\hline 4 & $5.20 \mathrm{~m}$ & 76.0 & & $5.20 \mathrm{~m}$ & 76.0 & \\
\hline 5 & $3.84,4.79 \mathrm{~m}$ & 64.4 & & $3.81,4.83 \mathrm{~m}$ & 64.4 & \\
\hline \multicolumn{7}{|c|}{$4-\mathrm{O}-\mathrm{SO}_{3} \mathrm{Na}$} \\
\hline \multicolumn{7}{|c|}{ Qui } \\
\hline 1 & $5.12 \mathrm{~d}(6.8)$ & 105.6 & C-2 (Xyl) & $5.12 \mathrm{~d}(7.1)$ & 105.5 & C-2 (Xyl) \\
\hline 2 & $4.22 \mathrm{~m}$ & 75.5 & & $4.19 \mathrm{~m}$ & 75.5 & \\
\hline 3 & $4.07 \mathrm{~m}$ & 76.5 & & $4.06 \mathrm{~m}$ & 76.4 & \\
\hline 4 & $3.76 \mathrm{~m}$ & 86.8 & & $3.73 \mathrm{~m}$ & 86.8 & \\
\hline 5 & $3.82 \mathrm{~m}$ & 72.1 & & $3.82 \mathrm{~m}$ & 72.1 & \\
\hline 6 & $1.79 \mathrm{~d}(4.9)$ & 18.2 & C-4, 5 (Qui) & $1.79 \mathrm{~d}(5.2)$ & 18.2 & C-4, 5 (Qui) \\
\hline \multicolumn{7}{|l|}{ Glc } \\
\hline 1 & $5.06 \mathrm{~d}(7.0)$ & 105.0 & C-4 (Qui) & $5.06 \mathrm{~d}(7.3)$ & 105.0 & C-4 (Qui) \\
\hline 2 & $4.20 \mathrm{~m}$ & 74.2 & & $4.16 \mathrm{~m}$ & 74.2 & \\
\hline 3 & $4.37 \mathrm{~m}$ & 88.1 & & $4.36 \mathrm{~m}$ & 88.1 & \\
\hline 4 & $4.23 \mathrm{~m}$ & 69.6 & & $4.16 \mathrm{~m}$ & 69.7 & \\
\hline 5 & $4.12 \mathrm{~m}$ & 77.8 & & $4.12 \mathrm{~m}$ & 77.8 & \\
\hline 6 & $4.33,4.53 \mathrm{~m}$ & 61.9 & & $4.31,4.55 \mathrm{~m}$ & 62.0 & \\
\hline \multicolumn{7}{|c|}{ 3OMeGlc } \\
\hline 1 & $5.42 \mathrm{~d}(7.6)$ & 106.0 & C-3 (Glc) & $5.41 \mathrm{~d}(7.7)$ & 106.0 & C-3 (Glc) \\
\hline 2 & $4.13 \mathrm{~m}$ & 75.1 & & $4.12 \mathrm{~m}$ & 75.2 & \\
\hline 3 & $3.78 \mathrm{~m}$ & 88.1 & & $3.78 \mathrm{~m}$ & 88.1 & \\
\hline 4 & $4.16 \mathrm{~m}$ & 70.7 & & $4.16 \mathrm{~m}$ & 70.8 & \\
\hline 5 & $4.08 \mathrm{~m}$ & 78.4 & & $4.07 \mathrm{~m}$ & 78.4 & \\
\hline 6 & $4.34,4.55 \mathrm{~m}$ & 62.2 & & $4.33,4.56 \mathrm{~m}$ & 62.3 & \\
\hline $\mathrm{OMe}$ & $3.94 \mathrm{~s}$ & 61.0 & & $3.94 \mathrm{~s}$ & 61.0 & \\
\hline
\end{tabular}

iment allowed the sequential assignment of most of the resonances for each sugar ring, staring from the easily distinguished signals due to anomeric protons. By the HMBC experiment, the location of the interglycosidic linkages was deduced, the signals of them were downfield relative to shifts expected for the corresponding methyl glycopyranosides: $\delta_{\mathrm{C}}$ 83.5 (Xyl C-2), $\delta_{\mathrm{C}} 86.8$ (Qui C-4), $\delta_{\mathrm{C}} 88.1$ (Glc C-3), ${ }^{13)}$ and a cross-peak between the $\mathrm{H}-1$ of $\mathrm{Xyl}$ and $\mathrm{C}-3$ of the aglycone indicated that the Xyl was connected to $\mathrm{C}-3$ of the aglycone, then the interglycosidic linkages could be deduced by the same way. The site of linkage of the sulfate group in the sugar units was determined by studying the NMR chemical shifts of the sugar moiety, C-4 (Xyl) shifted downfield to $76.0 \mathrm{ppm}$, indicating that the sulfate group was located at C-4 of the xylose unit. ${ }^{5)}$ The structure of the carbohydrate chain of 1 was corroborated by HMBC, COSY and NOESY correlations, see Fig. 2.

Combined with NMR data, it was showed that $\mathbf{1}$ and $\mathbf{3}$ have the same sugar sequence. ${ }^{5)}$ Thus, the structure of $\mathbf{1}$ was established to be 3-O-[3- $O$-methyl- $\beta$-D-glucopyranosyl$(1 \rightarrow 3)$ - $\beta$-D-glucopyranosyl- $(1 \rightarrow 4)-\beta$-D-quinovopyranosyl$(1 \rightarrow 2)-4-O$-sodiumsulfato- $\beta$-D-xylopyranosyl]-22-oxo9(11)-holostene- $3 \beta, 12 \alpha, 17 \alpha$-triol.

25-Hydroxy fuscocineroside B (2), colorless amorphous powder, was positive to Liebermann-Burchard and Molish tests. The molecular formula was established as $\mathrm{C}_{54} \mathrm{H}_{85} \mathrm{O}_{27} \mathrm{NaS}$ by the pseudomolecular ion $[\mathrm{M}+\mathrm{Na}]^{+}$at $\mathrm{m} / z$ 1243.4790 in the HR-ESI-MS (positive-ion mode). A fragment ion peak at $m / z 1123\left[\mathrm{M}+\mathrm{Na}-\mathrm{NaHSO}_{4}\right]^{+}$in the positive ion mode ESI-MS indicated the presence of a sulfate group in 2, which was confirmed by the IR spectrum with absorption bands at 1262 and $1208 \mathrm{~cm}^{-1}$. The IR spectrum also showed the presence of hydroxyl $\left(3421 \mathrm{~cm}^{-1}\right)$, carbonyl $\left(1773,1716 \mathrm{~cm}^{-1}\right)$, olefinic $\left(1651 \mathrm{~cm}^{-1}\right)$.

The aglycone of $\mathbf{2}$ differs from $\mathbf{3}$ by the presence of a hydroxyl at C-25, ${ }^{5}$ the signals of C-24 $\left(\mathrm{CH}_{2}\right), \mathrm{C}-25(\mathrm{C}), \mathrm{C}-26$ $\left(\mathrm{CH}_{3}\right)$ and $\mathrm{C}-27\left(\mathrm{CH}_{3}\right)$ were shifted downfield to 37.4, 69.0, 30.2 and $29.9 \mathrm{ppm}$. The HMBC spectrum showed crosspeaks $\mathrm{H}_{3}-26 / \mathrm{C}-25, \mathrm{H}_{3}-26 / \mathrm{C}-24, \mathrm{H}_{3}-27 / \mathrm{C}-25, \mathrm{H}_{3}-27 / \mathrm{C}-24, \mathrm{H}_{3}-$ $26 / \mathrm{C}-27$ and $\mathrm{H}_{3}-27 / \mathrm{C}-26$, together with the chemical shift of $\mathrm{C}-25$ supported the presence of the two methyl groups attached to C-25 bearing the hydroxyl group. Complete assignments were achieved by studying the results of HMQC, HMBC, COSY, and TOCSY experiment (Table 1). The $\alpha$ configuration of the $\mathrm{H}$ at $\mathrm{C}-17$ was confirmed by cross-peaks at $\delta_{\mathrm{H}} 3.19(\mathrm{H}-17) / 1.57(\mathrm{H}-21)$ and $\delta_{\mathrm{H}} 3.19(\mathrm{H}-17) / 1.28(\mathrm{H}-$ $30)$ in the NOESY spectrum ${ }^{10)}$ (see Fig. 3). Thus, the structure of the aglycone part of $\mathbf{2}$ was identified as a 22-oxo9(11)-holostene-3 $\beta, 12 \alpha, 25$-triol.

Combined with acid hydrolysis and NMR (see Table 2), it was found that the compounds $\mathbf{1}, \mathbf{2}$ and $\mathbf{3}$ all have the same sugar sequence. ${ }^{5)}$ Thus, the structure of $\mathbf{2}$ was established to be 3-O-[3-O-methyl- $\beta$-D-glucopyranosyl- $(1 \rightarrow 3)-\beta$-D-glucopyranosyl- $(1 \rightarrow 4)$ - $\beta$-D-quinovopyranosyl- $(1 \rightarrow 2)-4-O$-sodiumsulfato- $\beta$-D-xylopyranosyl]-22-oxo-9(11)-holostene$3 \beta, 12 \alpha, 25$-triol.

The Antifungal Activities Some triterpene glycosides hitherto isolated from sea cucumber exhibited significant antifungal activity. ${ }^{7)}$ In this paper, we report the antifungal activities of three triterpene glycosides isolated from $B$. mar- 


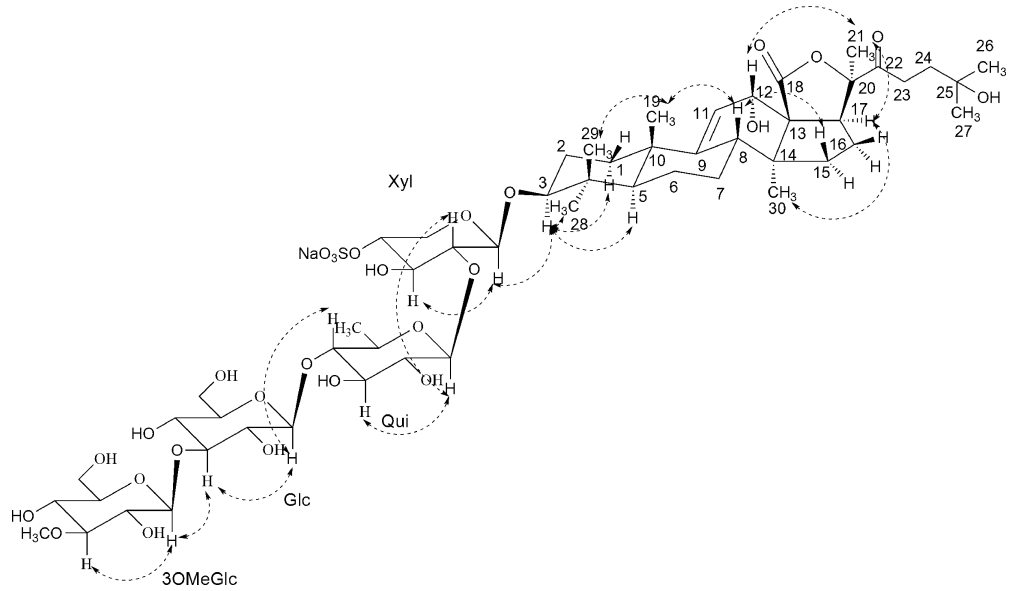

Fig. 3. The Key NOESY Correlations and Relative Configuration of $\mathbf{2}$

Table 3. Antifungal Activity of the Compounds $\left.\mathbf{1}-\mathbf{3}\left(\mathrm{MIC}_{80},{ }^{a}\right) \mu \mathrm{g} / \mathrm{ml}\right)$

\begin{tabular}{|c|c|c|c|c|c|c|}
\hline & Candida albicans & Cryptococcus neoformans & Aspergillus fumigatus & Trichophyton rubrum & Candida tropicalis & Candida krusei \\
\hline 1 & 64 & 16 & 16 & 16 & 64 & 64 \\
\hline 2 & $>64$ & $>64$ & $>64$ & $>64$ & $>64$ & $>64$ \\
\hline 3 & 64 & 16 & 16 & 16 & 64 & 64 \\
\hline TBNF & 4 & 1 & 0.0625 & 0.0625 & 0.0625 & $>64$ \\
\hline $\mathrm{KCZ}$ & 0.0625 & 0.0625 & 1 & 0.0625 & 0.0156 & 0.25 \\
\hline AMB & 0.25 & 0.25 & 4 & 4 & 0.25 & 2 \\
\hline FCZ & 0.25 & 0.25 & $>64$ & 4 & 0.25 & 4 \\
\hline
\end{tabular}

a) $\mathrm{MIC}_{80}$ : the minimum concentration to inhibit $\leq 80 \%$ growth for $\mathbf{1}-\mathbf{3}$ against six fungi strains.

morata against six strains: Candida albicans, Cryptococcus neoformans, Aspergillus fumigatus, Trichophyton rubrum, Candida tropicalis and Candida krusei. Terbinafine (TBNF), Ketoconazole (KCZ), Amphotericin B (AMB), Fluconazole (FCZ) were used as positive controls, and the results are shown in Table 3.

Earlier studies on the triterpene glycosides isolated from $B$. bivittata revealed that the presence of the $12 \alpha-\mathrm{OH}$ function seemed to be essential for exhibiting antifungal activities. ${ }^{7)}$ As we see in Table 3, 1 differs from 3 by the presence of a hydroxyl instead of a $\alpha-\mathrm{H}$ at $\mathrm{C}-17$, the antifungal activities were at the same level, but when the hydroxyl attaches to C-25 in the side chain, the antifungal activities decreased remarkably. It was envisioned that the better for the hydrophilic property of the side chain, the lower for the antifungal activities.

\section{Experimental}

General Melting points were determined on an XT5-XMT apparatus. Optical rotations were measured with a Perkin-Elmer 341 polarimeter. IR spectra were recorded on a Bruker Vector 22 infrared spectrometer. NMR spectra were recorded in $\mathrm{C}_{5} \mathrm{D}_{5} \mathrm{~N}$ on a Varian Inova- 400 spectrometer, and the 2D NMR spectra were obtained using standard pulse sequences. ESI-MS and HR-ESI-MS were recorded on a Micromass Quattro mass spectrometer. GC/MS were performed on a Finnigan Voyager apparatus using a DB-5 column $(30 \mathrm{~m} \times 0.25 \mathrm{~mm}$ i.d., $0.25 \mu \mathrm{m})$ with an initial temperature of $150^{\circ} \mathrm{C}$ for $2 \mathrm{~min}$ and then temperature programming to $300^{\circ} \mathrm{C}$ at a rate of $15^{\circ} \mathrm{C} / \mathrm{min}$. Semipreparative HPLC was carried out on an Agilent 1100 liquid chromatograph equipped with a refractive index detector using a Zorbax 300 SB-C18 column $(25 \mathrm{~cm} \times 9.4 \mathrm{~mm}$ i.d. $)$

Column chromatographies were performed on silica gel (200-300 mesh, 10-40 mm; Yantai, P. R. China) and ODS (40-63 mm; Merck) and Sephadex LH-20 (Pharmacia). Fractions were monitored by TLC (precoated silica-gel GF254 plates $(10-40 \mathrm{~mm}$; Yantai), and spots were visualized by heating Si gel plates sprayed with $10 \% \mathrm{H}_{2} \mathrm{SO}_{4}$ in EtOH

Six strains: Candida albicans (ATCC76615), Cryptococcus neoformans (ATCC32609), Aspergillus fumigates (Clinic Strains), Trichophyton rubrum (Clinic Strains), Candida tropicalis (Clinic Strains) and Candida krusei (Clinic Strains). Positive controls: Terbinafine (TBNF), Ketoconazole (KCZ), Amphotericin B (AMB), Fluconazole (FCZ).

Animal Material Specimens of B. marmorata were collected from offshore waters of Hainan island in the South China Sea in March 2006, and authenticated by Mr. Yu-Lin Liao (Institute of Oceanology, Chinese Academy of Science, P. R. China). A voucher specimen (No. BM-2006-3) was deposited at the Research Center for Marine Drugs, School of Pharmacy, Second Military Medical University, Shanghai.

Extraction and Isolation The dried sea cucumbers $(3.5 \mathrm{~kg})$ were chopped and refluxed with $60 \% \mathrm{EtOH}(31 \times 6,3 \mathrm{~h} / \mathrm{time})$, and evaporated under reduced pressure, and then suspended in 61 water, partitioned with $n$ $\mathrm{BuOH}$ for three times. The $n-\mathrm{BuOH}$ extract $(90 \mathrm{~g})$ was subjected to column chromatography on $\mathrm{Si}$ gel eluting with a $\mathrm{CHCl}_{3}: \mathrm{MeOH}: \mathrm{H}_{2} \mathrm{O}(10: 1: 0.1$; $9: 1: 0.1 ; 8: 2: 0.2 ; 7: 3: 0.5 ; 6: 4: 0.8)$ gradient to give 12 fractions. Fraction $10(11 \mathrm{~g})$ was further purified by reversed-phase silica MPLC eluting with an aq. $\mathrm{CH}_{3} \mathrm{OH}(40-80 \%)$ gradient to give 8 fractions. And then the fraction $7(0.5 \mathrm{~g}$ ) was purified by HPLC (Zorbax $300 \mathrm{SB}-\mathrm{C} 18 ; 70 \%$ aq. $\mathrm{MeOH}, 1.5 \mathrm{ml} / \mathrm{min})$ to afford the compounds $1(16 \mathrm{mg}), 2(15 \mathrm{mg})$ and 3 (35 mg).

17-Hydroxy Fuscocineroside B (1): Colorless amorphous powder; mp $224-226{ }^{\circ} \mathrm{C} ;[\alpha]_{\mathrm{D}}^{20}-0.2(c=0.675$, pyridine $) ;{ }^{1} \mathrm{H}-$ and ${ }^{13} \mathrm{C}-\mathrm{NMR}$ data, see Tables 1 and 2; ESI-MS (positive-ion mode) $m / z 1243[\mathrm{M}+\mathrm{Na}]^{+}, 1123$ $\left[\mathrm{M}+\mathrm{Na}-\mathrm{NaHSO}_{4}\right]^{+}$; ESI-MS (negative-ion mode) $\mathrm{m} / z 1197[\mathrm{M}-\mathrm{Na}]^{-}$. IR (KBr) $v_{\max }: 3421,1775,1717,1651,1265,1205,1076 \mathrm{~cm}^{-1}$. HR-ESI-MS (positive ion mode) $\mathrm{m} / \mathrm{z} 1243.4805[\mathrm{M}+\mathrm{Na}]^{+}$, (Calcd for $\mathrm{C}_{54} \mathrm{H}_{85} \mathrm{O}_{27} \mathrm{Na}_{2} \mathrm{~S}$, 1243.4794).

25-Hydroxy Fuscocineroside B (2): Colorless amorphous powder; mp $219-221^{\circ} \mathrm{C} ;[\alpha]_{\mathrm{D}}^{20}+8.3(c=0.41$, pyridine $) ;{ }^{1} \mathrm{H}-$ and ${ }^{13} \mathrm{C}-\mathrm{NMR}$ data, see Tables 1 and 2; ESI-MS (positive-ion mode) $\mathrm{m} / \mathrm{z} 1243[\mathrm{M}+\mathrm{Na}]^{+}, 1123$ $\left[\mathrm{M}+\mathrm{Na}-\mathrm{NaHSO}_{4}\right]^{+}$; ESI-MS (negative-ion mode) $\mathrm{m} / z 1197[\mathrm{M}-\mathrm{Na}]^{-}$. IR $(\mathrm{KBr}) v_{\max }: 3421,1773,1716,1651,1262,1208,1074 \mathrm{~cm}^{-1}$. HR-ESI-MS (positive ion mode) $\mathrm{m} / \mathrm{z} 1243.4790[\mathrm{M}+\mathrm{Na}]^{+}$, (Calcd for $\mathrm{C}_{54} \mathrm{H}_{85} \mathrm{O}_{27} \mathrm{Na}_{2} \mathrm{~S}$, 1243.4794) 
Acid Hydrolysis of 1-3 Each glycoside $(5 \mathrm{mg})$ was heated in an ampule with $5 \mathrm{ml}$ of aqueous $2 \mathrm{M} \mathrm{CF}_{3} \mathrm{COOH}$ at $120^{\circ} \mathrm{C}$ for $2 \mathrm{~h}$. The aglycone was extracted with dichloromethane, and the aqueous residue was evaporated under reduced pressure. Then $1 \mathrm{ml}$ of pyridine and $2 \mathrm{mg}$ of $\mathrm{NH}_{2} \mathrm{OH} \cdot \mathrm{HCl}$ were added to the dry residue, and the mixtures were heated at $90{ }^{\circ} \mathrm{C}$ for $1 \mathrm{~h}$. After the reaction mixtures were cooled, $1.5 \mathrm{ml}$ of $\mathrm{Ac}_{2} \mathrm{O}$ was added and the mixtures were heated at $90{ }^{\circ} \mathrm{C}$ for $1 \mathrm{~h}$. The reaction mixtures were evaporated under reduced pressure, and the resulting aldononitrile peracetates were analyzed by GC-MS using standard aldononitrile peracetates as reference samples. D-Xylose, D-quinovose, D-glucose, and 3-O-methyl-Dglucose were identified for each of $\mathbf{1}$ and $\mathbf{2}$ in a $1: 1: 1: 1$ ratio (D-quinovose: $t_{\mathrm{R}}=5.44 \mathrm{~min} ; \mathrm{D}$-xylose: $t_{\mathrm{R}}=5.53 \mathrm{~min} ; 3-O$-methyl-D-glucose: $t_{\mathrm{R}}=6.57 \mathrm{~min}$; D-glucose: $t_{\mathrm{R}}=6.75 \mathrm{~min}$ ).

Bioassays The antifungal activities of the compounds $\mathbf{1}-\mathbf{3}$ were tested against six strains: Candida albicans (ATCC76615), Cryptococcus neoformans (ATCC32609), Aspergillus fumigates (Clinic Strains), Trichophyton rubrum (Clinic Strains), Candida tropicalis (Clinic Strains) and Candida krusei (Clinic Strains). The antifungal activity data were evaluated by mensurating optical delnsity (OD) at $630 \mathrm{~nm}$ using Automatic Microplate Reader. ${ }^{14)}$ The drug $M I C_{80}$ was defined as the first well with an approximate $80 \%$ reduction in growth compared to the growth of the drug-free well. The data represented the means of three independent experiments in which each compound concentration was tested in three replicate wells. Terbinafine (TBNF), Ketoconazole (KCZ), Amphotericin B (AMB), Fluconazole (FCZ) were used as positive controls.

Acknowledgment This work was financially supported by National High-Tech Research and Development Project (863 Project, 2006AA09Z417 and 2006AA09Z423) and Chinese National Natural Science Foundation (Grant number: 20502035).

\section{References}

1) Sun P., Liu B. S., Yi Y. H., Li L., Gui M., Tang H. F., Zhang D. Z., Zhang S. L., Chemistry \& Biodiversity, 4, 450-457 (2007).

2) Zhang S. Y., Tang H. F., Yi Y. H., Fitoterapia, 78, 283-287 (2007).

3) Han H., Yi Y. H., Li L., Wang X. H., Liu B. S., Sun P., Pan M. X., Chinese Chem. Lett., 18, 161-164 (2007).

4) Zou Z. R., Yi Y. H., Wu H. M., Yao X. S., Du L. J., Wu J. H., Liaw C. C., Lee K. H., J. Nat. Prod., 68, 540-546 (2005).

5) Zhang S. Y., Yi Y. H., Tang H. F., J. Nat. Prod., 69, 1492-1495 (2006).

6) Zou Z. R., Yi Y. H., Wu H. M., Wu J. H., Liaw C. C., Lee K. H., J. Nat. Prod., 66, 1055-1060 (2003).

7) Kitagawa I., Kobayashi M., Hori M., Kyogoku Y., Chem. Pharm. Bull., 37, 61-67 (1989).

8) Stonik V. A., Elyakov G. B., "Bioorganic Marine Chemisty," Vol. 43, ed. by Scheuer P. J., Springer, Berlin, 1988

9) Kitagawa I., Kobayashi M., Inamoto T., Fuchida M., Kyogoku Y., Chem. Pharm. Bull., 33, 5214-5224 (1985).

10) Murray A. P., Muniain C., Seldes A. M., Maier M. S., Tetrahedron, 57 , 9563 (2001).

11) Stonik V. A., Kalinin V. I., Avilov S. A., J. Nat. Toxins, 8, 235 (1999).

12) Avilov S. A., Kalinin V. I., Smirnov A. V., Biochem. Syst. Ecol., 32, 715-733 (2004).

13) Breitmaier E., Voelter W., Carbon-13 NMR Spectroscopy [M], VCH, Weinheim, 1987.

14) Zhang J. D., Xu Z., Cao Y. B., S. Chen H., Yan L., An M. M., Gao P. H., Wang Y., Jia X. M., Jiang Y. Y., J. Ethnopharmacol., 103, 76-84 (2006). 